\title{
Cultura, arte e estética: uma análise da educação da sensibilidade a partir de
}

\author{
uma exposição
}

DOI: https://doi.org/10.22409/pragmatizes.v11i20.45792

\section{Angelina Accetta Rojas ${ }^{1}$ \\ André Cesari Batista de Lima ${ }^{2}$ \\ Lívia Ribeiro Barboza de Araújo Braga ${ }^{3}$}

\begin{abstract}
Resumo: O presente artigo busca abordar a relação entre arte, cultura e educação, através da experiência de alunos participantes da exposição "Almas do bem", realizada na Galeria de Arte La Salle, que fica localizada no Centro Universitário La Salle, Rio de Janeiro. Compreendendo que os processos de aprendizagem passam, pelos sentidos e pela capacidade de ver, sentir, ouvir, cheirar, provar e proporcionar os meios pelos quais se realiza uma interação do homem com o seu meio. Pensamos a Arte como área do conhecimento humano que abarca um amplo espectro de expressões e manifestações, podemos então relacionar a arte como possibilidade da promoção do elo entre o homem e o seu mundo, ou seja, um encontro pessoal, de expressão de linguagem e criação de sentido. Sendo assim, articular e promover a interface de diálogo entre educação, arte e cultura significa estabelecer objetivos, ações e metas, considerando a sua relação com as manifestações, expressões, produções artísticas e culturais.
\end{abstract}

Palavras-chaves: Arte; cultura; educação; exposição.

Cultura, arte y estética: un análisis de la educación en sensibilidad desde una exposición

Resumen: Este artículo busca abordar la relación entre arte, cultura y educación, a través de la experiencia de los estudiantes que participan en la exposición "Almas do bem", realizada en la Galería de Arte La Salle, ubicada en el Centro Universitário La Salle, Río de Janeiro. Entender que los procesos de aprendizaje pasan por los sentidos y la capacidad de ver, sentir, oír, oler, gustar y

\footnotetext{
${ }_{1}^{1}$ Angelina Accetta Rojas. Doutora em Educação pela Universidade Federal Fluminense. Professora Adjunta do Centro Universitário La Salle do Rio de Janeiro (Unilasalle-RJ). E-mail: angelina.rojas@lasalle.org.br - https://orcid.org/0000-0002-3091-7827

${ }^{2}$ André Cesari Batista de Lima. Mestrando pelo Programa de Pós-Graduação em Cultura e Territorialidade da Universidade Federal Fluminense. E-mail: andrecesari91@yahoo.com.br https://orcid.org/0000-0001-9809-1278

${ }^{3}$ Lívia Ribeiro Barboza de Araújo Braga. Mestranda em História Social pelo Programa de PósGraduação em História Social da UERJ/FFP. Coordenadora do Setor de Ação Comunitário e Pastoral do Centro Universitário La Salle do Rio de Janeiro (Unilasalle-RJ). E-mail: livia.braga@lasalle.org.br https://orcid.org/0000-0003-3416-4882
} 
proporcionar los medios por los que se produce la interacción del hombre con su entorno. Pensamos en el Arte como un área de conocimiento humano que abarca un amplio espectro de expresiones y manifestaciones, por lo que podemos relacionar el arte como una posibilidad de promover el vínculo entre el hombre y su mundo, es decir, un encuentro personal, de expresión del lenguaje y creación de significado. Por tanto, articular y promover la interfaz de diálogo entre educación, arte y cultura significa establecer objetivos, acciones y metas, considerando su relación con las manifestaciones, expresiones, producciones artísticas y culturales.

Palabras clave: Arte; educación; cultura; exposición.

Culture, art and aesthetics: an analysis of sensitivity education from an exhibition

\begin{abstract}
This article seeks to address the relationship between art, culture and education, through the experience of students participating in the exhibition "Almas do bem", held at the Galeria de Arte La Salle, which is located at Centro Universitário La Salle, Rio de Janeiro. Understanding that the learning processes pass, through the senses and the ability to see, feel, hear, smell, taste and provide the means by which a man's interaction with his environment takes place. We think of Art as an area of human knowledge that encompasses a wide spectrum of expressions and manifestations, so we can relate art as a possibility of promoting the link between man and his world, that is, a personal encounter, of expression of language and creation of meaning. Therefore, articulating and promoting the dialogue interface between education, art and culture means establishing objectives, actions and goals, considering their relationship with manifestations, expressions, artistic and cultural productions.
\end{abstract}

Keywords: Art; culture; education; exhibition.

\title{
Cultura, arte e estética: uma análise da educação da sensibilidade a partir de uma exposição
}

\section{Arte, educação e estética}

Vivemos em um mundo sujeito

a várias emergências e como humanidade, não estamos preparados.

O despreparo é grande diante das situações imprevistas, desde o mais simples do cotidiano, até o mais complexo, relacionado às mudanças climáticas e à pandemia que ameaçam a vida no planeta. Não podemos mais ignorar que o nosso mundo funciona em rede e de que essa dinâmica está presente em todas as dimensões da vida. Se por um lado tal questão está relacionada com a própria saúde planetária e com 0 modelo instrumental de progresso que adotamos, por outro lado tal dimensão está diretamente ligada à nossa sensibilidade, ou seja, à forma como o ambiente nos chega e nos penetra os sentidos.

Refletir sobre a Educação dos Sentidos significa perceber a relação entre corpo/mente/sensibilidade. Somos seres de linguagem e 
expressar significa existir. Dessa forma, podemos desvelar a educação como o desenvolvimento de possibilidades humanas, na pedagogia viva que eduque vivificando a percepção, os afetos, a inteligência e a imaginação. A criação é vital para a condição humana, para que cada um reconheça a sua voz, a sua capacidade de linguagem tanto no sentido de entender as emaranhadas redes de mensagens em que existimos, como no sentido de expressar-se mais livre e lucidamente.

A aprendizagem passa pelos sentidos, pela capacidade de ver, sentir, ouvir, cheirar, provar, e proporciona os meios pelos quais se realiza uma interação do homem com o seu meio. Freire nos diz que a educação, como prática estritamente humana, deve ser contrária à repressão de sonhos, desejos e experiências sem sentido (FREIRE, 1996).

Se pensarmos na Arte, como área do conhecimento humano que abarca um amplo espectro de expressões e manifestações, podemos então relacionar a arte como possibilidade da promoção do elo entre o homem e o seu mundo, ou seja, um encontro pessoal, de expressão de linguagem e criação de sentido. A esse respeito Fischer (1987) afirma que a arte é o elemento necessário para a união do indivíduo com o seu universo, capacitando-o a identificar-se com a vida dos outros e a incorporar em si aquilo que ele não é, mas tem a possibilidade de ser. Será preciso anunciar novos caminhos, novas propostas.

Assim, cabe à Arte a estimulação dos sentidos no processo educativo, para que o indivíduo seja transformador no desenvolvimento de suas habilidades perceptivas, tais como a sensorial, emocional e intelectiva.

A educação do sensível configura um vasto território do qual, sem dúvida, a Arte é um dos componentes. Nos domínios da educação estética (ou educação do sensível) acha-se compreendida a educação da sensibilidade como um esforço educacional em métodos e parâmetros. Tal mediação requer perceber os apelos que partem daqueles a ela submetidos, precisamente de seu corpo, com suas expressões de alegria e desejo, de dor e tristeza, de prazer e desconforto. 
É necessário utilizar uma base mais ampla que estude como o ser humano se apropria do mundo por meio do sensível em toda sua atividade.

O sensível é a condição de possibilidade da vida e do conhecimento. "Daí a tônica que é colocada [...] sobre a experiência estética: experiência artística, stricto sensu, experiência de religiosidade, tribalismo, preocupação com si, hedonismo multiforme, culto dos objetos, narcisismo coletivo etc.". (MAFFESOLI, 1996, p. 76).

Assim, estética e educação confluem na chamada educação estética, processo no qual intervém todo 0 conjunto de influências mencionadas. Cabe lembrar, como antecedente histórico, que Schiller (1759-1805) definiu as bases de uma educação estética como o sentimento educado pela beleza, pelo gosto e pelo impulso lúdico. É nesse estado que o homem experiencia "formas vivas".

Para isso seria necessário que sua forma fosse viva e sua vida, forma. Enquanto apenas meditamos sobre sua forma, ela é inerte, mera abstração; enquanto apenas sentimos sua vida, esta é informe, mera impressão. Somente quando sua forma vive em nossa sensibilidade e sua vida se forma em nosso entendimento o homem é forma viva (SCHILLER, 2002, p. 7778).

Schiller (2002), considera o Belo como algo objetivo e sua percepção como subjetiva. Dessa forma, a estética se encontra nos objetos e na natureza. O Belo não é limitação, mas infinitude, não é exclusão de certas realidades, mas é a inclusão absoluta de todas. No estado físico, o homem apreende 0 mundo de maneira passiva, apenas o sente. No estado estético, ele o coloca fora de si ou o contempla, sua personalidade se desloca, e o mundo surge diante de si. A contemplação, numa espécie de reflexão é a primeira relação liberal do homem com o mundo que o circunda, abrindo caminho de uma realidade comum a uma realidade estética e passagem dos meros sentimentos vitais a sentimentos de beleza.

Tampouco se pode, assim, negar a razão àqueles que declaram o estado estético o mais fértil em relação ao conhecimento e à moralidade. Eles estão perfeitamente certos; pois uma disposição da mente que compreende em si o todo da humanidade tem que, necessariamente, encerrar em si também cada uma de suas manifestações singulares segundo a 
faculdade; uma disposição da mente, que afasta do todo da natureza humana toda limitação, tem também que afastá-la de cada manifestação singular. (SCHILLER, 2002, p. 123)

Os métodos adotados para atingir os objetivos da educação estética devem considerar, segundo Read (1982), além da educação da sensibilidade, fundamentada no ajustamento dos sentidos ao seu ambiente, o fato de que tal ambiente não é inteiramente objetivo e sua experiência tampouco é apenas empírica. Dentro do indivíduo, existem "pátios interiores ou estados existenciais que podem ser exteriorizados pelo auxílio das faculdades estéticas" e esses níveis subconscientes "são um dos elementos fundamentais em todas as formas de atividade artística" (READ, 1982, p. 21).

Nesse sentido, a educação ultrapassa a mera ação de instruir e ensinar, para se constituir em um conjunto de práticas simbólicas, capaz de realizar a coesão e a integração do ser humano em um universo cultural polarizado. Se um homem é um ser antinômico que existe em duas dimensões essenciais, a individual e a social, uma educação que discrimine ou atrofie uma delas estará amputando o educando em sua humanidade.

Assim, uma educação que recupera a dimensão imaginária, simbólica, pode contribuir, conforme Duborgel (1995), para reequilibrar, harmonizar na economia do ser humano o ser imaginante, o ser físico e o sujeito do pensamento direto, deixando de ter caráter meramente reprodutório na medida em que permite, isto é, exige a criatividade e a inventividade.

Ostrower (1998, p. 12) afirma que grande parte da sensibilidade, incluindo as sensações internas, permanece vinculada ao inconsciente. Todas as formas de autorregulagem e as reações involuntárias do nosso organismo pertencem à sensibilidade. Todavia, outra parte que participa do sensório chega ao nosso consciente de forma articulada e organizada. Dessa forma, chamamos de percepção a elaboração mental das sensações. Na ordenação dos dados sensíveis, estruturam-se os níveis do consciente, pois, ao apreender o mundo, o homem compreende um princípio configurador seletivo. Ostrower (1998) discorre, ainda, sobre 
a concepção de sensibilidade como uma "disposição elementar, num permanente estado de excitabilidade sensorial, como porta de entrada das sensações" (OSTROWER, 1998, p. 13). A mediação do conhecimento como experiência é influenciada por diferentes linguagens, bem como pelo repertório cultural e emocional do indivíduo.

Para Dewey (2004), experiência é conhecimento, para Freire (1984) é a consciência da experiência que podemos chamar conhecimento. Já Eisner (2002) destaca da experiência do mundo empírico sua dependência de nosso sistema sensorial biológico, que é a extensão de nosso sistema nervoso, o qual Susane Langer (1980) chama de "órgão da mente".

Há duas fontes de conhecimentos historicamente construídas pelo homem: a sensibilidade (intuições representadas no espaço e no tempo, através das percepções e sentidos) e o entendimento (produtor de conceitos). Em outras palavras, o conhecimento só se verifica quando existe uma íntima relação entre 0 sentir e 0 pensar.
A respeito da estética e criação de sentido, Marcos Villela Pereira (1996, p. 85) desenvolve o que chama de uma "tentativa de ressignificação para o estudo sobre a estética do cotidiano". O autor busca resgatar uma "diferença dentro da estética", que ele estabelece pelas designações de "macroestética" e microestética". Esclarece, ainda, que não se trata de designações de quantidade ou extensão, mas "se referem à natureza e à ordem de existencialização". Assim, para o autor, a macroestética refere-se a "uma estética com ' $E$ ' maiúsculo que nasce no século XVIII, como campo epistemológico independente, como disciplina". Já a microestética "se refere ao modo como cada indivíduo se organiza enquanto subjetividade. É a ordem da processualidade dos "campos interativos de forças vivas da exterioridade ao perpassar o sujeito em prática". Refletindo sobre a especificidade entre a macro e a microestética, diz o autor: "assim, a primeira é produto de uma subjetividade que quer se instituir como modelo homogeneizante [por exemplo, nos conceitos de belo, de criatividade], enquanto a segunda é 
ROJAS, Angelina A.; LIMA, André Cesari B. de; BRAGA, Lívia Ribeiro B. de A. Cultura, arte e estética: uma análise da educação da sensibilidade a partir de uma exposição. PragMATIZES - Revista Latino-Americana de Estudos em Cultura, Niterói/RJ, Ano 11, n. 20, p. 236-254, março 2021.

processo de produção de subjetividades". Trata-se, então, da forma pela qual apreendemos 0 mundo, ou seja, "o mundo toma sentido para nós, de acordo com a maneira pela qual nos afeta e pela qual nós o afetamos" (PEREIRA, 1996, p. 127)

Partindo-se da ideia de Alexander Baumgarten (1714-1762), o fundador da Estética (ciência do conhecimento sensível), não há outro conhecimento a não ser "formações mapeando formações". Do ponto de vista dessa definição, não apenas há diferença entre arte e ciência como também se faz Arte na física, na química, da mesma forma que na poesia. Dessa forma, pensar uma estética equivale a pensar toda $\mathrm{e}$ qualquer prática do homem. Há, no entanto, polos de atração artísticos e científicos. Em seu trabalho Estética, a lógica da arte e do poema, o criador da estética filosófica adverte que "as representações sensíveis [...] devem ser conhecidas a partir do discurso sensitivo" (BAUMGARTEN, 1973, p. 65).

As aparências das coisas do mundo, isto é, suas formas, surgem como expressivas e portadoras

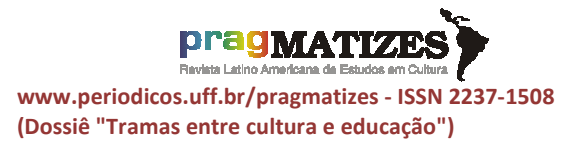

simbólicas de sentimentos humanos, como capazes de espelhar e revelar emoções, intensidades de vibração diante da vastidão do real. Dessa forma, podemos dizer que cada objeto, cada percepção estética, é único, não importando sua similitude com 0 conjunto de seus congêneres. Sua forma é particular, o que nos remete à percepção pessoal.

Além da percepção do estímulo visual, é importante considerar o que a experiência estética proporciona, ao defini-la como aquela que permite ao observador perceber, sentir e experienciar uma obra de arte, gerando uma ativação dos sistemas sensório motor, emocional e cognitivo. Assim, uma experiência estética pode ser avaliada levando em consideração a resposta emocional ao objeto estético, com o prazer estético que a imagem proporciona, ou somente considerando-se o julgamento estético feito, mas relacionado com aspectos cognitivos.

De qualquer forma, a beleza permanece como ponto central das discussões sobre experiências estéticas. O entendimento das bases neurais da percepção e da resposta à beleza pode nos fornecer um insight 
sobre a percepção e resposta à arte visual em si.

Os estudos que emergem nessa área atestam que prestar mais atenção às propriedades visuais de expressões plásticas aumenta a atividade em áreas do córtex cerebral visual. Julgamentos estéticos ativam partes do córtex pré-frontal relacionadas com tomada de decisão e respostas com relação ao prazer estético que a arte proporciona, pois ativam áreas cerebrais relacionadas com emoções básicas e mecanismos relacionados com resposta a estímulos ambientais recompensadores. É importante notar que essas áreas neurais relacionadas com emoção e recompensa são ativadas automaticamente, mesmo quando não se solicita às pessoas que falem explicitamente se avaliam o que estão vendo como bonito ou feio.

Segundo Eco (1988), a estruturação da obra aberta indica a maneira de expressar um problema estético, é uma tendência interpretativa que podemos seguir. A função da arte aberta (imagem), como metáfora epistemológica, oferece-se como mediadora entre "a abstrata categoria da metodologia científica e a matéria viva de nossa sensibilidade; quase como uma espécie de esquema transcendental que nos permite compreender novos aspectos do mundo" (ECO, 1988, p. 158).

Arte, estética e cultura estão intrinsecamente relacionadas. A todo momento, o ser humano relaciona-se com a arte produzindo, criando, apreciando ou interpretando, o que comprova que a arte faz parte da subjetividade humana. A arte traz em si uma codificação específica, pois é construção não-verbal e inter-relação entre sujeito e objeto, entre conhecimento e sensações, entre pensar, sentir, fazer e refletir.

A obra de arte nos obriga a repensar o que temos por realidade, fazendo-nos perceber a possibilidade concreta da inauguração de outras realidades. A arte nos convence de que o mundo em que vivemos não é único mundo possível.

Assim, somamos e multiplicamos muitas sabedorias, pois arte, homem e mundo são fios que constroem a grande teia do porvir. Os sentidos de conhecimento espelham e movimentam a evolução e conjecturam as forças do entendimento sensível dos elementos bem como suas variadas formas de apresentação 
descortinando-se, assim, em novas visões, do homem e do mundo.

A produção sensível e sua relação com a existência e experiências humanas geram um conhecimento de natureza diverso daquele que a ciência propõe. Assim, na valorização e no desenvolvimento da sensibilidade haverá a possibilidade de contribuir de forma inegável, na criação de projetos que vislumbrem estratégias expressivas com indivíduos autores, sujeitos de criação e sentido.

Os paradigmas da pósmodernidade apontam para o diálogo dos saberes, na interatividade cotidiana de um mundo globalizado, que mistura linguagens e culturas. Nas palavras de Irina Bokova, Diretorageral da UNESCO (2010, p. 12), "a diversidade cultural e o diálogo entre as culturas contribuem para 0 surgimento de um novo humanismo, no qual se reconciliam o universal e o local, e mediante o qual reaprendemos a construir o mundo".

A integração do saber global com o saber local é uma meta a ser alcançada dia a dia. A força de cada espaço que se propõe à prática das manifestações artísticas atinge 0 propósito da UNESCO (2010) no intuito de criar identidade e sentidos praticando a universalização e o reforço das identidades locais de cada espaço e sua comunidade envolvente.

Incluir a Arte no currículo de forma transversal, interdisciplinar e abrangente é uma proposta da UNESCO (2005) para que atribua o devido valor a uma ciência de grande utilidade na formação integral e sensível dos estudantes. Logo, a pósmodernidade pode acrescentar todas as formas de estilo, gênero e movimentos e a arte contemporânea torna-se cada vez mais livre de seus suportes, pois ao expandir-se, ocupa as mídias e as redes sociais, inaugurando novas leituras e experimentações no universo do webespaço.

Dentre as oito competências necessárias para a aprendizagem ao longo da vida, referida também por mecanismos de certificação e validação como Education \& Training 2010 e European Qualifications Framework (EQF) for Lifelong Learning, lista-se a expressão artística e cultural. Sem arte e sem educação pela arte, a expressão cultural dos povos seria extremamente reduzida. 
Segundo Fossatti, Hengemule e Casagrande (2011, p. 79), a dimensão estética, como a dimensão ética, constitui o humano e, como tal, precisa ser considerada nos processos educacionais. Sua relevância está em consonância à importância da sensibilidade, do gosto e da diferença como elementos centrais para a vida das pessoas e das comunidades humanas.

Paulo Freire (1984) afirma ser essencial ao processo educativo o seu caráter formador, que vai além de oferecer um treinamento puramente técnico e se volta para a democratização da cultura, a tomada de consciência do ser humano como agente autônomo, crítico e político.

O reconhecimento da dimensão da arte no cotidiano universitário e na formação do futuro profissional é refletir sobre o problema do estético como algo intrínseco ao ato de educar. A sensibilidade $\mathrm{e}$ as emoções concentram grande efetividade para a orientação do agir e do transformar, além da formação técnica, e, ao mesmo tempo, apontam outro caminho, diverso daquele do racionalismo clássico e dos fundamentos puramente abstratos. A estética demonstra que a educação não é possível sem um ethos da diferença e da pluralidade.

A efetividade da dimensão estética para a formação humana pode ser verificada na possibilidade de entendermos os processos de subjetivação - de formação do humano - como processos, também estéticos. Ou seja, conceitos como 'cuidado de si', 'estilística da existência' e 'vida como obra de arte' começam a fazer sentido a partir da assunção da singularidade, da diferença e do particular como noções inegociáveis do processo de subjetivação do humano (FOSSATTI; HENGEMULE; CASAGRANDE, 2011, p. 80).

\section{A Galeria de Arte La Salle como espaço de ensino e aprendizagem}

O Núcleo de Arte e Cultura, setor responsável pela Galeria, traz como objetivos proporcionar subsídios para ações vinculadas ao ensino, pesquisa e extensão, promovendo e apoiando ações de caráter multidisciplinar de arte, lazer, cultura, cidadania e ética. Além do mais, com o propósito de promover exposições e 
ROJAS, Angelina A.; LIMA, André Cesari B. de; BRAGA, Lívia Ribeiro B. de A. Cultura, arte e estética: uma análise da educação da sensibilidade a partir de uma exposição. PragMATIZES - Revista Latino-Americana de Estudos em Cultura, Niterói/RJ, Ano 11, n. 20, p. 236-254, março 2021.

eventos culturais e artísticos - que educam o olhar e os sentidos - o NAC visa consolidar o diálogo intercultural, com a parceria de instituições sociais, culturais e diplomáticas, buscando a diversidade na descoberta de novos olhares.

$\mathrm{Na}$ Galeria, sua abordagem, está construída a partir das ações e inter-relações sociais no ambiente universitário, tendo 0 intuito de promover a interação e a construção de histórias de vida, onde os hábitos e costumes, manifestações, expressões e sentimentos estão inseridos, identificando cada indivíduo, determinando o seu modo de viver, de ser e de se expressar. Considerando a Lei de Diretrizes Básicas da Educação Superior (1996), esta prioriza o estímulo à criação cultural, do espírito científico e do pensamento reflexivo (Capítulo IV, artigo 43, I), com o objetivo de desenvolver 0 entendimento do homem e do meio em que vive. Já a Declaração Universal sobre a Diversidade Cultural (UNESCO, 2002), constata que a cultura se encontra no centro dos saberes contemporâneos sobre a identidade, a coesão social e o

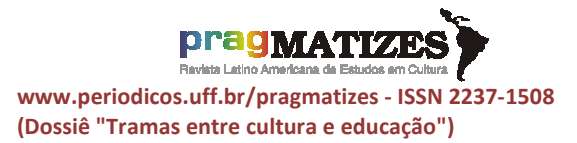

desenvolvimento de uma economia fundada no saber.

Dessa forma, podemos afirmar que os direitos culturais são parte integrante dos direitos humanos, que são universais, indissociáveis e independentes e que é missão da Universidade promover o intercâmbio cultural e o desenvolvimento da capacidade criadora que alimentam a vida em sociedade. O reconhecimento da dimensão da arte no cotidiano universitário e na formação do futuro profissional é refletir sobre o problema do estético como algo intrínseco ao ato de educar. A sensibilidade e as emoções concentram grande afetividade para a orientação do agir e do transformar, além da formação técnica e, ao mesmo tempo, apontam outro caminho, diverso daquele do racionalismo clássico e dos fundamentos puramente abstratos. A estética demonstra que a Educação não é possível sem um ethos da diferença e da pluralidade.

Os elementos do ambiente da Galeria de Arte, incorporada ao Núcleo de Arte e Cultura do Centro Universitário La Salle constituem objetos de aprendizagem e pesquisa que se descortinam mais ampla e 
ROJAS, Angelina A.; LIMA, André Cesari B. de; BRAGA, Lívia Ribeiro B. de A. Cultura, arte e estética: uma análise da educação da sensibilidade a partir de uma exposição. PragMATIZES - Revista Latino-Americana de Estudos em Cultura, Niterói/RJ, Ano 11, n. 20, p. 236-254, março 2021.

profundamente à luz da visão artística e das inspirações imagéticas. Por intermédio da arte, da imaginação e da criatividade, pode-se reconstruir o real e, consequentemente, crenças, ideias, expectativas, o que auxilia na construção do conhecimento. Assim, a relação entre arte, cultura, imaginação, sensibilidade e conhecimento implica os conceitos de arte e expressões imaginárias como vetores significativos de descobertas que aproximam sujeito e objeto do conhecimento com experiências estéticas e sensíveis do "ir e vir" no caminho do corredor cultural, Galeria de Arte.

A emergência do ser poético e da consciência sensível não é, a priori, anterior à experiência estética; ambos - ser e consciência - fazem parte dessa experiência, que associa estranhamento e indagações, percepções sensíveis e imaginação criadora, realidade e transcendência. Freire nos diz que:

a partir das relações do homem com a realidade, resultantes de estar com ela e de estar nela, pelos atos de criação, recriação e decisão, ele vai dinamizando seu mundo. Vai dominando a realidade. Vai humanizando-a. Vai acrescentando a ela algo que ele mesmo é fazedor (FREIRE, 2006, p. 51).

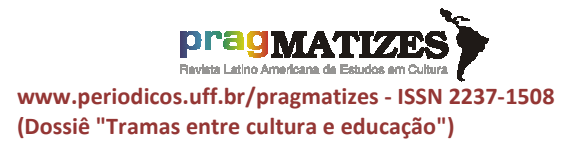

No ano de 2019, a Galeria La Salle realizou a exposição Almas do Bem, que contou com a participação da artista plástica Raquel Pádua e de seis alunos do projeto social Moleques do Bem, desenvolvido pela autora. Esse projeto, acontecia aos sábados no Projeto Desabrochar - que é uma parceria entre o Setor de Ação Comunitária e Pastoral (SEAC) do Unilasalle-RJ e o Centro Social Vicenta Maria - no bairro Santa Rosa, em Niterói.

O Projeto social Moleques do Bem foi apresentado primeiramente na Obra Social Salesiana em novembro de 2018, tendo como foco de atendimento crianças e adolescentes entre 8 e 13 anos. Gerou como resultados um livro didático do Moleque de Pé e seus amigos de 22 páginas, uma empresa fictícia e a exposição na Galeria La Salle. A mostra trouxe três séries: duas da artista Raquel Pádua (Explosão de Sentimentos e Liberdade da Alma) e a série Almas do Bem, que apresentou o quadro feito pelos alunos, além de outras artes visuais, do livro com os personagens e a turma de 14 amigos que viraram bonecos que as crianças desenvolveram na Oficina. 
ROJAS, Angelina A.; LIMA, André Cesari B. de; BRAGA, Lívia Ribeiro B. de A. Cultura, arte e estética: uma análise da educação da sensibilidade a partir de uma exposição. PragMATIZES - Revista Latino-Americana de Estudos em Cultura, Niterói/RJ, Ano 11, n. 20, p. 236-254, março 2021.
A exposição aconteceu como encerramento de um longo projeto de formação cultural e artística, desenvolvida com esses jovens. Após aulas de arte abstrata e técnicas de pintura, os jovens foram apresentados a um desafio, produzirem arte de forma intencional para participarem de uma exposição na Galeria La Salle. O entusiasmo e a auto estima foram notórios. $E$ todos do meio social desses meninos foram atingidos. Os familiares vieram a exposição, assim como professores e colegas. Percebeu-se assim como a produção artística, a exposição e o projeto em si têm potencial para transformar a autoestima e a vida dos envolvidos.

Com o objetivo de oferecer um espaço/tempo repleto de intenções, ainda que inconsciente, como o Núcleo de Arte e Cultura/Galeria de Arte, é incitar as faculdades simbólicas para a busca do profissional integral, cujo pensamento não será comandado pela opinião alheia, muito menos por editoriais de jornais. Seria o início de pensarmos uma educação na qual obter o diploma e alcançar um emprego não seria o principal, mas, sim, compreender o que se passa à nossa volta e desenvolver um sentido pessoal do que é a experiência: de olhar para sentir, sentir para perceber e perceber para transformar.

As mediações, no processo de fruição, auxiliam a ultrapassar as fronteiras das percepções superficiais. Convocam, não somente as pessoas, mas os corpos em suas inteirezas, complexidades e sociabilidades. O sujeito ao vivenciar as técnicas, estratégias e exercícios propostos pelos mecanismos de mediação no caminho da Galeria, que vão muito além da informação, envolve-se e dedica-se à apreciação da obra desenvolvendo as suas potencialidades cognitivas, sensíveis, críticas e estéticas.

Rose Hikiji (2005), analisou a performance de jovens músicos, através do projeto Guri, que conta com aulas de música para jovens considerados de baixa renda e alta vulnerabilidade social. Ao compreender 0 processo da performance com os alunos a autora diz que:

A performance é central em projetos que, como o Guri, têm como um dos objetivos principais a intervenção social por meio da música. Ela torna visíveis atores e instituição. É palco de um amplo jogo de espelhos, lugar de exibição de identidade e construção de autoimagens. É espaço de transformação. É 
ROJAS, Angelina A.; LIMA, André Cesari B. de; BRAGA, Lívia Ribeiro B. de A. Cultura, arte e estética: uma análise da educação da sensibilidade a partir de uma exposição. PragMATIZES - Revista Latino-Americana de Estudos em Cultura, Niterói/RJ, Ano 11, n. 20, p. 236-254, março 2021. concebida como auge do processo pedagógico, locus de exibição do que foi aprendido, ensaiado, incorporado. É oportunidade de conhecer novos lugares, pessoas, é "saída para o mundo". (HIKIJI, 2005, p. 158)

Compreendo que a performance envolvida em projetos sociais, está vinculada a diversos fatores e que a formação dos beneficiários em áreas consideradas mais carentes, criam uma noção de pertencimento e reconhecimento através da cultura. A partir da criação desses projetos em áreas consideradas de risco na cidade, percebe-se uma relação entre a ocupação do tempo ocioso de jovens, com a ideia de afastamento da criminalidade e seu ambiente.

\begin{abstract}
Tais pensamentos têm como princípio a noção de que o tempo "ocioso" é um tempo perigoso. É preciso, afirma-se, ocupar o tempo. Fato curioso é que tal necessidade seja colocada em contextos muito diversos: na Febem, na periferia de São Paulo ou de outras capitais, nos centros urbanos em geral, inclusive entre famílias de classe média ou alta. O "perigo" do tempo livre une crianças e jovens separados pela desigualdade social e cultural ímpar em nosso país. (HIKIJI, 2006, p. 155)
\end{abstract}

Sovik (2014), pontua que o surgimento de projetos sociais no Rio de Janeiro, aparecem com força nos anos 1990, devido ao processo de democratização governamental instalado, o qual faz a violência policial contra a população pobre e negra entrar em pauta. Além disso, a autora apresenta que a partir de marcos violentos como a chacinas da Candelária e de Vigário Geral, levaram à fundação da Casa da Paz, do Viva Rio, e do AfroReggae.

O impacto dos projetos sobre a cena pública nacional vem, em parte, da reconhecida relação entre autorrepresentação e capacidade de ação. Os depoimentos entusiasmados são muitos, de participantes, quadros e lideranças desses projetos, e fazem sentido. A autoestima pode não ser suficiente, mas é condição necessária para "os de baixo" reconhecerem a própria capacidade e sentirem a liberdade de agir para mudar as relações sociais. A experimentação com novas narrativas sobre si é fundamental para abrir um espaço no mundo, para "entrar em cena", como disse certa vez o teatrólogo e diretor Paul Heritage, experiente protagonista da cena de projetos socioculturais no Brasil e no Reino Unido. (SOVIK, 2014, p. 174)

\section{Palavras}

como

autorrepresentação e autoestima, são cruciais na abordagem de projetos sociais. Ou seja, o objetivo principal de um projeto social, não é apenas formar esse indivíduo em uma habilidade técnica ou artística, mas sim trabalhar e abordar também essas noções perante seus alunos e frequentadores.

Observando a relevância de oferecer espaços lúdicos e formativos no tempo livre, o Projeto Desabrochar 
ocupa o final de semana, quando menos projetos estão disponíveis para atender a essas crianças e adolescentes. Nesse sentido, o trabalho voluntário é a última peça a ser encaixada nesse cenário. Com o apoio de iniciativas voluntárias como o 'Moleques de Bem', o projeto oferece diferentes oportunidades de aprendizado.

No caso do "Moleques de Bem", os talentos da voluntária foram colocados à disposição para estimular novos talentos e possibilidades no campo das artes plásticas. O estímulo a ampliação do repertório cultural desses beneficiários é objetivo específico em diversas atividades que vão se construindo no projeto.

Em relação ao tema cultura, este tem adquirido um espaço importante nos debates da sociedade contemporânea, sendo este um conceito com múltiplos sentidos e disputas. No meio acadêmico deixou de ser apenas assunto das ciências sociais, ganhando atenção também em outras áreas de conhecimento. A cultura, construída a partir das ações e inter-relações sociais no ambiente universitário tem o intuito de promover a interação e a construção de histórias de vida, onde os hábitos e costumes, manifestações, expressões e sentimentos estão inseridos, identificando cada indivíduo, determinando o seu modo de viver, de ser e de se expressar. Este ao longo dos anos ganhou múltiplos sentidos, podendo ser apontado como característico deste conceito, o interesse multidisciplinar de diversas áreas de estudo.

Clifford Geertz (2008), considera a cultura como redes de significação em que a humanidade está envolta. Raymond Williams (2000), entende a cultura como o processo significante através do qual, uma ordem social é comunicada, reproduzida, experimentada e explorada, além disso, para o autor, o termo contém em si mesmo uma tensão entre produzir e ser produzido. Diante disto, podemos compreender a cultura como processos sociais, nos quais acontecem embates e negociação, em que sentidos e valores são construídos, atribuídos, vivenciados socialmente, sendo que os sentidos e significados não estão dados, são constantemente disputados (EAGLETON, 2003). 


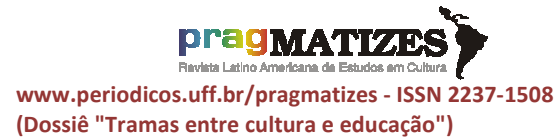

Para Tylor (2009, p. 69) "Cultura ou Civilização, tomada em seu mais amplo sentido etnográfico, é aquele todo complexo que inclui conhecimento, crença, arte, moral, lei, costume e quaisquer outras capacidades e hábitos adquiridos pelo homem na condição de membro da sociedade”. Já o conceito de cultura no lluminismo, fundamentava-se na hegemonia de grupos dominantes a partir da ideia de racionalidade. $\mathrm{O}$ sentido antropológico - que assume que todas as sociedades e grupos produtores de Cultura - quanto o sentido lluminista - que afirma que existem sociedades ou grupos mais cultos que outros - se equiparam ao pensar a Cultura como uma unidade que se constitui por meio de confronto, na negociação e na imposição de uns e outros.

Além do mais, a concepção de cultura está sempre em disputa, sem perder seu lugar característico, e principalmente por ocupar um lugar central no mundo contemporâneo. Para Hall (1997), a cultura assume uma função de centralidade, pois, apesar de nem tudo se reduzir a cultura, tudo é atravessado por ela, já que cultura é produção de sentido.
Segundo Hall (2016), a "representação é uma parte essencial do processo pelo qual os significados são produzidos e compartilhados entre os membros de uma cultura. Representar envolve o uso da linguagem, de signos e imagens que significam ou representam objetos" (HALL, 2016, p. 31). Além disso, para o autor, é através da representação que trazemos sentido às coisas, o que faz com que se tenha a possibilidade de ter uma noção da nossa própria identidade, e também, esta ideia é constantemente reelaborada conforme o período em que vivemos, as nossas experiências e também pela interação social, sendo através da concepção desses sentidos que vão ser reguladas as nossas práticas e condutas no grupo em que vivemos. Através da linguagem, esses sentidos são criados e passados, podendo ser dos mais variados tipos, como a escrita, a fala, imagens ou objetos, linguagem corporal e também a música.

A forma ou a interpretação de uma obra é embasada numa teia de conceitos que foram criados na história individual. Por sensibilidade, entendemos o filtro da percepção. Pela 
ROJAS, Angelina A.; LIMA, André Cesari B. de; BRAGA, Lívia Ribeiro B. de A. Cultura, arte e estética: uma análise da educação da sensibilidade a partir de uma exposição. PragMATIZES - Revista Latino-Americana de Estudos em Cultura, Niterói/RJ, Ano 11, n. 20, p. 236-254, março 2021.

teia, entendemos a construção do conhecimento.

Nas palavras de Prigogine (1996, p. 26):

Atualmente, o mundo que vemos fora de nós e o mundo que vemos dentro de nós estão se convergindo. Essa convergência é, talvez, um dos eventos culturais mais importantes da nossa era. Onde o mundo interior e o mundo exterior se tocam, aí se encontra o centro da alma.

A partir do pensamento de Prigogine (1996), podemos considerar que a arte em um ambiente acadêmico seja algo de significativa importância, considerando a participação da comunidade acadêmica, como fruidores (sujeitos que sentem, percebem e experienciam as diferentes formas de expressão artística), que estimulam a emoção e a construção do conhecimento.

\section{Considerações finais}

Articular e promover a interface de diálogo entre educação, arte e cultura significa estabelecer objetivos, ações e metas, considerando a sua relação com as manifestações, expressões, produções artísticas e culturais. Se a educação forma pelo e para o diálogo, ela pode e deve ser continuamente enriquecida por outros campos de saberes, por diferentes tradições culturais, interculturais, artes e inovações.

Neste trabalho, apresentamos uma experiência que aliou a arte e a educação. Os resultados ressaltam a importância do espaço da Galeria La Salle, em uma Universidade, ao estimular de forma sensorial e reflexiva a vivência da diversidade cultural, promovendo educação voltada para os direitos humanos.

A partir do presente artigo compreendemos que é central a inclusão de experiências estéticas diversificadas como elementos de plasticidade e visibilidade no cotidiano acadêmico. Tais experiências requerem a educação do olhar e do sentir, do perceber, do criar e do transformar e podem ser efetivadas mediante $\mathrm{o}$ contato com diferentes formas de expressão, bem como no desenvolvimento do gosto musical e na apreciação da cultura popular e erudita. Possibilitar que a cultura faça parte do cotidiano da universidade, utilizando concepções do imaginário habitual, propicia a criação de relações representativas, pois a visibilidade permite uma apreensão significativa dos sentidos. Ao ressignificarmos 0 conhecimento, envolvemos, 
ROJAS, Angelina A.; LIMA, André Cesari B. de; BRAGA, Lívia Ribeiro B. de A. Cultura, arte e estética: uma análise da educação da sensibilidade a partir de uma exposição. PragMATIZES - Revista Latino-Americana de Estudos em Cultura, Niterói/RJ, Ano 11, n. 20, p. 236-254, março 2021.

necessariamente, a criatividade e a sensibilidade, e, assim, aproximamos a arte da educação $e$, consequentemente, da vida.

\section{Referências bibliográficas}

BAUMGARTEN, Alexander. Estética:a lógica da arte e do poema. Coletânea de textos extraídos de Johann Cristian Kleyb de 1750. Petrópolis: Vozes, 1993.

BRASIL. Lei $\mathrm{n}^{\circ}$ 9.394, de 20 de dezembro de 1996. Lei de diretrizes e bases da educação nacional. Brasília: 1996.

DEWEY, John. Experiencia $y$ educación. Madrid: Biblioteca Nueva, 2004.

DUBORGEL, Bruno. Imaginário e pedagogia. Lisboa: Instituto Piaget, 1995.

EAGLETON, Terry. A ideia de cultura. Lisboa: Temas e Debates, 2003.

ECO, Umberto. Obra aberta. São Paulo: Perspectiva, 1988.

EISNER, Elliot W. The arts the creation of mind. New Haven: Yale University Press, 2002.

FISCHER, Ernst. A necessidade da Arte. Rio de Janeiro: Guanabara, 1987.

FOSSATTI, Paulo; HENGEMULE, Edgard; CASAGRANDE, Cledes. (Orgs.). Ensinar a bem viver. Canoas: Editora Unilasalle, 2011.

FREIRE, Paulo. Ação cultural para a liberdade. Rio de Janeiro: Paz e Terra, $7^{\mathrm{a}}$ ed. 1984.

FREIRE, Paulo. Educação como prática da liberdade. São Paulo: Paz e Terra, 2006.
FREIRE. Paulo. Pedagogia da autonomia: saberes necessários à prática educativa. São Paulo: Paz e Terra, 1996.

GEERTZ, Clifford. A interpretação das culturas. Rio de Janeiro, LCT, 2008.

HALL, Stuart. A centralidade da cultura: notas sobre as revoluções culturais do nosso tempo. Educação e Realidade, Porto Alegre, v. 22, n. 2, jul./dez. 1997.

HALL, Stuart. Cultura e representação. PUC-Rio: Apicuri, 2016.

HIKIJI, Rose Satiko Gitirana. Etnografia da performance musical: identidade, alteridade e transformação. Horiz. antropol., Porto Alegre, v. 11, n. 24, p. 155-184, dez. 2005. Disponível em:

http://www.scielo.br/scielo.php?script= sci_arttext\&pid=S0104-

71832005000200008\&lng=pt\&nrm=iso.

HIKIJI, Rose Satiko Gitirana. Música para matar o tempo intervalo, suspensão e imersão. Mana, Rio de Janeiro, v. 12, n. 1, p. 151-178, abr. 2006. Disponível em: http://www.scielo.br/scielo.php?script= sci arttext\&pid=S0104-

93132006000100006\&lng=pt\&nrm=iso.

LANGER, Susane. Sentimento e forma. São Paulo: Perspectiva, 1980.

MAFFESOLI, Michel. No fundo das aparências. Rio de Janeiro: Vozes, 1996.

OSTROWER, Fayga. Criatividade e processos de criação. Rio de Janeiro: Vozes, 1998.

PARLAMENTO EUROPEU. Conselho da União Europeia. Recomendação 2006/962. Competências essenciais para a aprendizagem ao longo da vida. 2006. Disponível em: http://eur- 
lex.europa.eu/JOHtml.do?uri=OJ:C:20 07:287:SOM:pt:HTML. Acesso em: 12 jul. 2013.

PEREIRA, Marcos Villela. Estética da professoralidade: um estudo interdisciplinar sobre a subjetividade do professor. São Paulo: PUCSP, 1996. Tese (Doutorado em Educação), PPG Educação - Supervisão e Currículo, 1996.

PRIGOGINE, llya. O fim das certezas. São Paulo: Editora Unesp, 1996.

READ, Herbert. A educação pela arte. São Paulo: Martins Pontes, 1982.

SCHILLER. Friedrich. A educação estética do homem. São Paulo: lluminuras, 2002.

SOVIK, Liv. Os projetos culturais e seu significado social. Galaxia (São Paulo, Online), n. 27, p. 172-182, jun. 2014.

TYLOR, Edward Barnett. A ciência da cultura. In: CASTRO, Celso (org.). Evolucionismo cultural. Rio de Janeiro: Zahar, 2009.

UNESCO. Cultura de paz: da reflexão à ação; balanço da Década Internacional da Promoção da Cultura de Paz e Não Violência em Benefício das Crianças do Mundo. - Brasília: UNESCO; São Paulo: Associação Palas Athena, 2010. Disponível em: http://unesdoc.unesco.org/images/001 8/001899/189919por.pdf. Acesso em: 15 jul. 2013.

UNESCO. Década da Educação das Nações Unidas para um Desenvolvimento Sustentável, 20052014: documento final do esquema internacional de implementação. Brasília: UNESCO, 2005. Disponível em:

http://unesdoc.unesco.org/images/001 3/001399/139937por.pdf. Acesso em: 15 jul. 2013.
WILLIAMS, Raymond. Cultura. São Paulo: Paz e Terra, 2000. 